\title{
Laparoscopic assisted ventriculoperitoneal shunt revisions as an option for pediatric patients with previous intraabdominal complications
}

\author{
Revisão de derivações ventrículo-peritoneais assistidas por videolaparoscopia como uma \\ opção para pacientes pediátricos com complicações intra-abdominais
}

Fernanda O. de Carvalho', Antonio R. Bellas ${ }^{1}$, Luciano Guimarães², José Francisco Salomão

\begin{abstract}
Multiple shunt failure is a challenge in pediatric neurosurgery practice and one of the most feared complications of hydrocephalus. Objective: To demonstrate that laparoscopic procedures for distal ventriculoperitoneal shunt failure may be an effective option for patients who underwent multiple revisions due to repetitive manipulation of the peritoneal cavity, abdominal pseudocyst, peritonitis or other situations leading to a "non reliable" peritoneum. Method: From March 2012 to February 2013, the authors reviewed retrospectively the charts of six patients born and followed up at our institution, which presented with previous intra-peritoneal complications and underwent ventriculoperitoneal shunt revision assisted by video laparoscopy. Results: After a mean follow-up period of nine months, all patients are well and no further shunt failure was identified so far. Conclusion: Laparoscopy assisted shunt revision in children may be, in selected cases, an effective option for patients with multiple peritoneal complications due to ventriculo-peritoneal shunting.
\end{abstract}

Keywords: hydrocephalus, ventriculoperitoneal shunt, abdominal pseudocyst, laparoscopic surgery.

\section{RESUMO}

Múltiplas disfunções de derivações ventrículo-peritoneais em pacientes crônicos são complicações temidas no tratamento das hidrocefalias e um desafio na prática neurocirúrgica. Objetivo: Demonstrar que a abordagem laparoscópica para o tratamento das obstruções distais das derivações ventrículo-peritoneais é uma opção eficaz em pacientes submetidos a múltiplas revisões, manipulação repetitiva da cavidade abdominal, pseudocisto abdominal, peritonite ou outras complicações indutoras de peritônio "não confiável". Método: Os autores revisaram retrospectivamente, de março de 2012 a fevereiro de 2013, os prontuários de seis pacientes nascidos e acompanhados em um hospital pediátrico, que apresentaram múltiplas complicações intraperitoneais e tiveram a revisão de derivações ventrículo-peritoneais assistida por videolaparoscopia. Resultados: Todos os pacientes melhoraram clinicamente e nenhuma outra disfunção foi identificada após um período de acompanhamento médio de 9 meses. Conclusão: Revisão distal de derivações ventrículoperitoneais assistida por videolaparoscopia em crianças é, em casos selecionados, uma opção eficaz para pacientes crônicos com história de múltiplas complicações peritoneais.

Palavras-chave: hidrocefalia, derivação ventrículo-peritoneal, pseudocisto abdominal, cirurgia laparoscópica.

Surgical treatment of hydrocephalus accounts for most of pediatric neurosurgical procedures and ventriculo-peritoneal shunting (VP shunt) remains the main option of treatment and also a major concern regarding complications ${ }^{1,2,3}$. Shunt complications, defined as obstruction, overdrainage, loculation or infection, sometimes demands difficult solutions with high surgical morbidity and mortality ${ }^{1,2,3,4}$.
Abdominal complications of VP shunt are not rare and the main causes of distal catheter failure are related to extra peritoneal retraction of the catheter, incisional hernia, subcutaneous or intrabdominal cerebrospinal fluid (CSF) collections. These complications tend to get worse with multiple peritoneal revisions and additional complications such as hemoperitoneum, shunt infection and

${ }^{1}$ Serviço de Neurocirurgia Pediátrica, Instituto Nacional da Saúde da Mulher, Criança e Adolescente Fernandes Figueira, Instituto Fernandes Figueira, Fundação Oswaldo Cruz, Rio de Janeiro RJ, Brazil;

${ }^{2}$ Serviço de Cirurgia Pediátrica, Departamento de Cirurgia Pediátrica, Instituto Nacional da Saúde da Mulher, Criança e Adolescente Fernandes Figueira, Instituto Fernandes Figueira, Fundação Oswaldo Cruz, Rio de Janeiro RJ, Brazil.

Correspondence: Fernanda Oliveira de Carvalho; Rua Mario Covas Junior 335/301; 22631-030 Rio de Janeiro RJ - Brasil; E-mail: neurofe@hotmail.com Conflict of interest: There is no conflict of interest to declare.

Received 24 September 2013; Received in final form 14 November 2013; Accepted 03 December 2013 
peritonitis, which may result in fibrosis and peritoneal sclerosis 5 .

Patients with multiple abdominal revisions, abdominal pseudocyst (APC) or peritonitis often end up as ventriculoatrial shunting (VAS) candidates, with known risks of endocarditis, atrial fibrillation, tromboembolyc events and complications related to direct manipulation of the blood vessels ${ }^{2,6}$.

Our purpose is to show that laparoscopic approach may be an option for patients submitted to multiple revisions due to APC, shunt infection, peritonitis or other conditions leading to a "non reliable" peritoneum. It is our aim to show that laparoscopic shunt revision for distal ventriculoperitoneal shunt failure allows best distal catheter positioning and lysis of peritoneal adhesions minimizing risk factors to a "non reliable" peritoneum. Finally, the lack of reports of this technique in the Brazilian literature justifies this communication.

\section{METHOD}

We have retrospectively reviewed the charts of six patients born, treated and followed up at our institution who underwent multiple abdominal catheter revisions. A summary of the data is shown in Table.

Five out of six patients studied were males. Their age at the laparoscopic procedure ranged from 3 to 13 years old (mean 7 years).

Five out of six patients were first shunted in the first month of life. Two patients had congenital hydrocephalus; two had myelomeningocele and Chiari type II malformation; one child had an atretic occipital encephalocele; and another had mucopolysaccharidosis.

All patients eventually needed shunt externalization. Nineteen external ventricular drains (EVDs) were inserted (mean 3.16 drains per patient). Shunt revisions were performed in 15 patients with uneven distribution, varying from one to four in the six cases. The two patients with treated myelomeningocele had higher complication rates when compared to the other four patients.

One third of the patients were admitted with abdominal distension and Blumberg sign. In this group, APC were found during abdominal sonography. Other two patients had distal obstruction, with free fluid inside the peritoneal cavity and no sign of APC at sonography. Two out of six patients had fever, leucocitosis and infected CSF at admission. The two with ventriculitis had Meticilin resistant Staphylococcus aureus (MRSA) colonization at diagnosis.

The patients with infection or APC history had their shunts externalized or removed. All were submitted to external ventricular drainage, and treated with antibiotics. According our protocol, three sequential CSF samples with negative cultures were needed before laparoscopic insertion of the new shunt at each case.

Surgical technique: Our protocol to prevent shunt infection was largely inspired by Choux et al. ${ }^{7}$ and Faillace's studies $^{8}$. Surgical drapes are placed in order to allow minimal skin exposure and cauterization is avoided as much as possible. Surgical gloves are changed and a new set of instruments is used for catheter manipulation. The shunt system with unidirectional valve is protected in order to avoid direct contact with the skin and hands. The distal end of the catheter is manipulated exclusively under laparoscopic view. After connecting the system distal, spontaneous CSF drainage is checked before closing the cranial wound.

The technique used by the pediatric surgery team has been already described: the abdominal trocar is safely introduced through a five millimeters umbilical port, $\mathrm{CO}_{2}$ is safely insufflated up to $10-12 \mathrm{mmHg}$ in the peritoneal cavity. The abdominal cavity is locally inspected using a 30 lens connected through this same trocar. With this maneuver, omental adhesions, fibrosis and hypertrophy are identified and removed with the aid of a blunt forceps 9

A suitable intraperitoneal place is selected and the distal tip of the peritoneal catheter is hence positioned: either at a newly created bundle-free spot, at the retro hepatic space or at any other retro-omental space were catheter free migration with peristaltic movements can be ensured. Therefore the risk of catheter blocking is minimized (Figures $1 \mathrm{~A}$ and 1B). Pneumoperitoneum is undone, the trocather is pulled out, hemostasis is reviewed and the wound is closed.

\section{RESULTS}

All patients showed fibrotic bundles at laparoscopic inspection: they were mainly located at the previous laparotomy sites,

Table. Patient clinical data.

\begin{tabular}{cccccc}
\hline & Demography & Etiology & EVD & Causes / number of revisions & Follow-up time \\
\hline 1 & M, 8y & MPS & 3 & Distal obstruction (2) & $10 \mathrm{~m}$ \\
2 & M, 6y & CH & 1 & APC (2) & $10 \mathrm{~m}$ \\
3 & M, 3y & ENC & 3 & APC (1) + VAS obstruction (1) & $10 \mathrm{~m}$ \\
4 & M, 6y & MMC & 4 & Distal obstruction (3) & $9 \mathrm{~m}$ \\
5 & M, 7y & CH & 3 & CSF infection (3) & $9 \mathrm{~m}$ \\
6 & F, 13y & MMC & 5 & CSF infection (4) & $6 \mathrm{~m}$ \\
\hline
\end{tabular}

APC: abdominal pseudocyst; CH: congenital hydrocephalus; ENC: encephalocele; EVD: external ventricular drain; MMC: myelomeningocele; MPS: mucopolysaccharidosis; VAS: ventriculoatrial shunt; CSF: cerebral spinal fluid. 

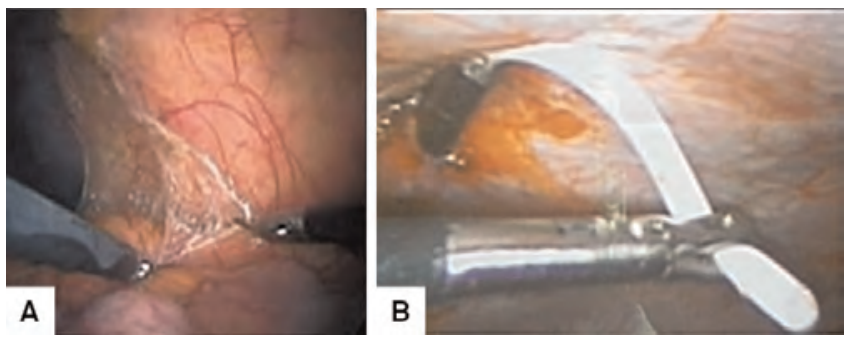

Figure 1. Laparoscopic view of distal catheter placement: Through one previous incision and single trocather view is possible to diagnose and break fibrotic bundles, inspect omental and peritoneal surfaces (A); follow distal shunt function and ensure best distal catether placement (B).

at the pseudocyst and at local infection location. The mucopolysaccharidosis patient showed diffuse bundles but also revealed one week bundle formation at the latest laparotomy site.

All patients showed immediate recovery and are being regularly followed at the outpatient unit. None has presented further shunt or abdominal complications so far (Figures 2A and $2 \mathrm{~B}$ ). One patient had a transient intraperitoneal free fluid collection demonstrated through ultrasonography, which resolved spontaneously. The follow-up time ranges from 6 to 10 months, with a mean time of 9 months.

\section{DISCUSSION}

The differential diagnosis of acute abdomen in patients with VPS may encompass a wide spectrum of underlying diseases ${ }^{4,6,10,11}$. Patients with underlying chronic diseases such as MPS and myelomeningocele have higher complication rates than others with isolated hydrocephalus because of several associated risk factors. Most of the abdominal shunt complications have a similar clinical presentation with overlapping symptomatology, including abdominal pain, tenderness, nausea, vomiting, and fever ${ }^{3,6,11}$.

Sainte-Rose et al demonstrated that $30 \%$ of shunts would fail in the first year after implantation and that $70 \%$ of all the
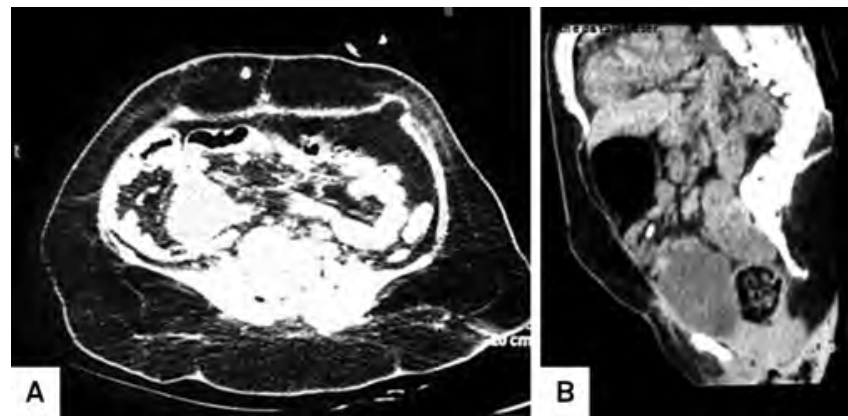

Figures 2A and 2B. Postoperative CT scan three months after laparoscopy showing a good positioning of the distal catheter and absence of free fluid or any abdominal complications. shunts will have to be replaced after ten years ${ }^{3}$. Kestle et al. found similar results showing that $62 \%$ of shunts were functioning one year after implantation, and that less than $20 \%$ were still working after ten years ${ }^{12}$.

Some data on complications related to peritoneal dialysis (PD) catheter might guide us about the physiopathology of peritoneal failure. Just as happens in patients submitted to PD, peritonitis, blood, and the amount of previous abdominal accesses are predictors of peritoneal catheter performance ${ }^{3}$.

The mechanisms leading to failure of peritoneal shunting are similar to those leading to failure of PD. The success of $\mathrm{PD}$, and consequently, peritoneal absorption and catheter function, depends on the structural and functional integrity of the peritoneal membrane, as stated by Young 5 . Mesothelial cells line the peritoneal membrane and are responsible for peritoneal repair and inflammation. Chronically, after peritonitis, they detach from their underlying basement membrane and expose the submesothelium. As infiltrating and resident peritoneal cells are activated, synthesis of proinflammatory cytokines and matrix proteins increases and the basement membrane reduplicates ${ }^{5}$. Transdifferentiated mesothelial cells have a greater fibrogenic potential and thus contribute to the deposition of matrix proteins and fibrin in the submesothelium, hyalinization of blood vessels, and vasculopathy. If not controlled, these alterations will lead to thickening of the submesothelium. Ultimately peritoneal fibrosis and sclerosis will take place leading to inability to fluid absorption and, consequently, to inevitable shunt failure ${ }^{5}$.

According to a French-Canadian cooperative study, the probability of shunt dysfunction after 12 years of follow-up is $81 \%$ and there was a higher risk of shunt failure in the first year of follow-up (around 30\% of the cases) which increased at a rate of $2-5 \%$ per year ${ }^{3}$. The study showed that $56.1 \%$ of shunt dysfunctions were caused by catheter obstruction, $30 \%$ of which related to the distal tubing ${ }^{3}$.

Several alternative procedures have been reported as a temporary or permanent solution to VPS failure, such as the Torkildsen procedure, ventriculopleural shunt, ventriculo-renal shunt, ventriculoureteral shunt, ventriculovenous shunt and ventriculosagittal shunt $t^{4,10,13,14,15,16,17,18,19,20}$.

The aforementioned procedures present a higher rate of complication when compared to VAS and all are considered third choice alternatives ${ }^{7,8,9,10,11,12,13,14,15,16}$. This is especially true in children under 8 year-old with restricted lung capacity, scoliosis or urinary system malformations ${ }^{10}$.

Several studies demonstrated that more than $44 \%$ of the patients with distal VPS complications had multiple abdominal revisions due to APC or peritonitis and end up as VAS candidates ${ }^{3,11,21}$.

One should however keep in mind that VAS is not devoid of risks. In long-term follow-up, infection and obstruction rates have been reported to be as high as 
$29 \%$ and $55 \%$ respectively ${ }^{2,19,22}$. Additionally, atrial stimulation triggered by the distal catheter might cause several kinds of cardiac arrhythmia and shunt infection may lead to endocarditis responsible for high morbidity and mortality rates $^{2,19,22,23}$. Furthermore, 7\% of these patients have cardiopulmonary thromboembolism ${ }^{2}$ and there is also a risk of glomerulonephrytis ${ }^{23}$.

As a tertiary level pediatric hospital, our Institution deals with lifelong complications of high risk patients, including the ones with the so-called "non reliable" peritoneum and those with sclerosed neck vessels, unable to be used as receptacle for CSF after multiple shunt revisions.

Aware of all the risks and of the natural history of VAS we started looking for options, which could offer less morbidity and fewer complications. In 1979, Morgan ${ }^{24}$ introduced peritoneoscopy to treat VPS complications in children. This procedure didn't become popular because of the high complication rates ${ }^{22}$. In 1993, with the technical and technological advance, Armbruster et al. ${ }^{25}$ and Basauri et al. ${ }^{26}$ described the laparoscopically assisted implantation of ventriculoperitoneal shunts and, in 1995 $\mathrm{Kim}^{27}$ first described the laparoscopic management of an APC.

\section{References}

1. Berry JG, Hall MA, Sharma V, Goumnerova L, Slonim AD, Shah SS. A multi-institutional, 5-year analysis of initial and multiple ventricular shunt revisions in children. Neurosurgery 2008;62:445-454.

2. Kulkarni AV, Shams I. Quality of life in children with hydrocephalus: results from the Hospital for Sick Children, Toronto. J Neurosurg 2007;107(5 Suppl):S358-S364.

3. Sainte-Rose C, Piatt JH, Renier D, et al. Mechanical complications in shunts. Pediatr Neurosurg 1991;217:2-9.

4. Yamashita K, Yonekawa Y, Kawano T, et al. Intra-abdominal cyst following revision of ventriculoperitoneal shunt - case report. Neurol Med Chir (Tokyo) 1990;30:748-752.

5. Yung S, Chan TM. Pathophysiological changes to the peritoneal membrane during PD-related peritonitis: the role of mesothelial cells. Mediators Inflamm 2012;2012:484167.

6. Yavuz C, Demırtas S, Calıskan A, et al. Reasons, procedures, and outcomes in ventriculoatrial shunts: a single-center experience. Surg Neurol Int 2013;4:10.

7. Choux M, Genitori L, Lang D, Lena G. Shunt implantation: reducing the incidence of shunt infection. J Neurosurg 1992;77:875-880.

8. Faillace WJ. A no-touch technique protocol to diminish cerebrospinal fluid shunt infection. Surg. Neurol 1995;43:344-350.

9. Hasson HM, Rotman C, Rana N, Kumari NA. Open laparoscopy: 29years experience. Obstetric Gynecol 2000;96:763-766.

10. Chung JJ, Yu JS, Kim JH, Nam SJ, Kim MJ. Intraabdominal complications secondary to ventriculoperitoneal shunts: CT findings and review of the literature. Am J Roentgenol 2009;193:1311-1317.

11. Martin K, Baird R, Farmer JP, et al. The use of laparoscopy in ventriculoperitoneal shunt revisions. J Pediatr Surg 2011;46:2146-2150.

12. Kestle J, Drake J, Milner R, et al. Long-term follow-up data from the Shunt Design Trial. Pediatr Neurosurg 2000;33:230-236.
In the current literature, a Database Systematic Review on this matter reported no significant difference between open and laparoscopic techniques for PD catheters insertion $^{28}$. Conversely, a review article compared open versus laparoscopic insertion of the peritoneal catheter in ventriculoperitoneal shunt placement, and the laparoscopy group had shorter surgical time, shorter hospitalization period, less blood loss and a smaller distal catheter obstruction rate ${ }^{29}$. Other studies demonstrated that laparoscopic distal shunt revisions might be a valuable option and a long lasting complication free procedure for selected patients ${ }^{13,22,27,29}$. To our best knowledge, there are no similar reports in the Brazilian literature and our initial experience is in accordance with the series already published. The six patients with previous peritoneal complications and several shunt revisions improved dramatically after laparoscopy assisted shunt revision without any further shunt failure so far.

In conclusion, we believe that laparoscopy assisted shunt revision in selected cases might be a less invasive and more effective option for patients with multiple intrabdominal manipulation. The laparoscopic approach allowed us a better catheter positioning, lysis of fibrotic bundles and peritoneal inspection as well, without any additional complication.

13. Behrendt $H$, Nau HE. Ventriculo-renal shunt in the therapy of hydrocephalus. Urologe A 1987;26:331-333.

14. Ehni G, Moiel RH, Bragg TG. A Torkildsen's ventriculocisternostomy: some complications and their prevention. Clin Neurol Neurosurg 1976;79:119-132.

15. El-Shafei IL. Ventriculovenous shunt against the direction of blood flow: a new approach for shunting the cerebrospinal fluid to the venous circulation. Childs Nerv Syst 1985;1:200-207.

16. Elwatidy SM. Ventriculo-sagittal sinus shunt malfunction. Causes of failure, avoidance, and alternatives. Neurosciences (Riyadh) 2009;14:172-174.

17. Pal K, Jindal V. Ventriculo cholecystic shunt in the management of hydrocephalus. Indian Pediatr 2007;44:435-437.

18. Pittman T, Steinhardt G, Weber T. Ventriculo-ureteral shunt without nephrectomy. Br J Neurosurg 1992;6:261-263.

19. Samtleben W, Bosch T, Bauriedel G, et al. Internal medicine complications of ventriculoatrial shunt. Med Klin (Munich) 1995;90:67-71.

20. Willison CD, Kopitnik TA, Gustafson R, Kaufman $\mathrm{HH}$. Ventriculopleural shunting used as a temporary diversion. Acta Neurochir (Wien) 1992;115:67-68.

21. Salomão JF, Leibinger RD. Abdominal pseudocysts complicating CSF shunting in infants and children. Report of 18 cases. Pediatr Neurosurg 1999;31:274-278.

22. Bhasin RR, Chen MK, Pincus DW. Salvaging the "lost peritoneum" after ventriculoatrial shunt failures. Childs Nerv Syst 2007;23:483-486.

23. Haffner D, Schindera F, Aschoff A, Matthias S, Waldherr R, Schärer K. The clinical spectrum of shunt nephritis. Nephrol Dial Transplant 1997;12:1143-1148. 
24. Morgan WW. The use of peritoneoscopy in the diagnosis and treatment of complications of ventriculoperitoneal shunts in children. J Pediatr Surg 1979;14:180-181.

25. Armbruster C, Blauensteiner J, Ammerer HP, Kriwanek S. Laparoscopically assisted implantation of ventriculoperitoneal shunts. J Laparoendosc Surg 1993;3:191-192.

26. Basauri L, Selman JM, Lizana C. Peritoneal catheter insertion using laparoscopic guidance. Pediatr Neurosurg 1993;19:109-110.
27. Kim HB, Raghavendran K, Kleinhaus S. Management of an abdominal cerebrospinal fluid pseudocyst using laparoscopic techniques. Surg Laparosc Endosc 1995;5:151-154.

28. Xie H, Zhang W, Cheng J, He Q. Laparoscopic versus open catheter placement in peritoneal dialysis patients: a systematic review and meta-analysis. BMC Nephrol 2012;13:69.

29. Hagen SM, van Alphen AM, Ijzermans JN, Dor FJ. Laparoscopic versus open peritoneal dialysis catheter insertion, the LOCl-trial: a study protocol. BMC Surg 2011;11:35. 